\title{
Unskilled Migration, Child labor and Human Capital Accumulation of Children in the Presence of Parental Absenteeism
}

\author{
Yumna Hasan* and Waqar Wadho ${ }^{* *}$
}

\begin{abstract}
Temporary unskilled migration and the remittances it generates have the potential to reduce child labor and improve educational outcomes in developing countries. However, recent literature points towards the adverse impact of the parental absenteeism on children left behind. We build a theoretical model to explore the joint impact of remittances and parental absenteeism on child labor and human capital formation of children left behind in the context of unskilled workers' migration. We find threshold conditions for the relative wage of source to destination countries beyond which unskilled migration helps in reducing child labor and increasing human capital. Moreover, the threshold is endogenous and depends on the sensitivity of human capital formation to parental absenteeism relative to the child's time spent on acquiring human capital. In a special case when the former is equal to the latter, the wages in the destination country should at least be twice as much as in the source country to have a detrimental (promoting) impact on child labor (human capital formation). Since the importance of parental absenteeism would depend on a variety of sociocultural factors such as marriage, presence of extended families, religious communities, and social networks, there will be heterogeneity in the impact of unskilled migration.
\end{abstract}

Keywords: Migration, child labor, parental absenteeism; human capital.

JEL Classification: F22, F24, J24, O15.

\section{Introduction}

The last few decades have witnessed a significant increase in the international migration of unskilled workers from developing countries. This rise in migration flows internationally have also been associated with

\footnotetext{
* MPhil graduate, Lahore School of Economics, Lahore, Pakistan.

** Assistant Professor \& Senior Research Fellow, Lahore School of Economics, Barki Road Lahore. Email.w.wadho@lahoreschool.edu.pk
} 
an increase in remittances (Ratha et al., 2011). Temporary unskilled migration and the remittances that result from it may reduce child labor and increase educational attainment in developing countries. However, recent literature also points towards the adverse impact of parental absenteeism on children left behind. In this article, we build a theoretical model to explore the joint impact of remittances and parental absenteeism on child labor and human capital formation of the children left behind in the context of unskilled workers' migration. The article builds on three fundamental premises observed in the migration literature: first, migration has important implications for the education of children; second, migration and child education are joint decisions taken by parents; and third, human capital impacts economic growth.

There is overwhelming evidence showing the positive impact of migration and resulting remittances on the schooling outcomes of the children left behind. In particular, the literature identifies the dual role of remittances in enhancing school enrolment on one hand while reducing child labor on the other (see Acosta, 2006; Arif \& Chaudhry, 2015; Calero et al., 2007; Mansuri, 2006; Yang, 2008). Hanson and Woodruff (2003) found that children belonging to households with an emigrant complete more years of schooling and this effect is particularly large for girls. Similarly, Cox Edwards and Ureta (2003) report that remittances significantly enhance school retention and reduce drop outs. This holds true irrespective of the amount of remittances received. Furthermore, Dorantes et al. (2010) found that not only does migration increase school enrollment and enhance the school retention, it also reduces child labor.

The theoretical literature on the other hand predominantly models the migration decision in the context of high skilled workers. Several theoretical papers show that the prospect of migrating to countries where education entails higher returns leads to higher education attainment in anticipation of potential future migration (Beine et al., 2001; Beine et al., 2008; Mayr \& Peri, 2009 Mountford, 1997; Stark \& Wang, 2002). This branch of theoretical work underscores the role of greater prospective returns for human capital existing in foreign countries that affects the decision to accumulate human capital at home. Another branch of theoretical work deals with how the prospect of their children emigrating in the future induces parents to invest in their children's education (Chen, 2006; Marchiori et al., 2010). 
Understanding the determinants and implications of unskilled labor migration is crucial for two reasons. First, unskilled migration forms a large portion of the emigration from developing countries. According to Ahn (2004), the bulk of the people emigrating from the South Asian countries of Bangladesh, Nepal, Sri Lanka, India and Pakistan constitute unskilled manpower. For example, the proportion of unskilled workers in total workers emigrating from a developing country like Sri Lanka was greater than 70 percent in 2002. Second, unskilled migration is important for the growth of a developing country and is not associated with the negative consequences noted of migration such as brain drain (Bhagwati \& Hamada 1974; Faini 2007; Rapoport 2002; Richard \& Adams 2009; Nimi et al., 2010). These studies highlight how migration of skilled labor puts developing countries at a disadvantage by not only draining the source country of its skilled workforce but also because skilled labor sends back less remittances as compared to unskilled workers.

In this study, we construct a model of human capital formation in which the emigration of parents and the remittances that they send back influence economic growth in the source country through the human capital accumulation of their children. We propose that unskilled workers are forward-looking and therefore make joint decisions to emigrate and to send back remittances. Unskilled workers migrate to avail the wage premiums offered by the destination countries but leave their children behind. In such an environment, the migrating parents undertake three crucial decisions: the total duration of migration; the amount of remittances send back to dependent children, and the time their children should devote to education. Parental remittances finance the consumption of the child; however, the children might have to supplement these remittances by engaging in child labor.

We model migration and child education as a joint decision taken by the migrating parents. Empirical literature clearly acknowledges migration and child education as interdependent decisions and authors have taken steps to tackle this endogeneity issue (Acosta, 2006; Calero et al., 2009; Dorantes et al., 2010; Ebeke, 2012; Hanson \& Woodruff, 2003; Mansuri, 2006; Yang, 2008). The theoretical literature on skilled migration has also treated migration as endogenous when people incorporate the probability to migrate while undertaking educational investment decisions (Beine et al., 2001; Beine et al., 2008; Chen, 2006; Mayr and Peri, 2009; Marchiori et al., 2010; Mountford, 1997; Stark and Wang, 2002). We introduce human capital accumulation technology that is a function of remittances and parental absenteeism. Thus, migration on one hand 
positively affects human capital accumulation of the child through remittances, and negatively due to parental absenteeism.

The adverse impact of parental absenteeism is also well documented in the empirical literature. The human capital of children is adversely affected by parental migration due to three main reasons. Firstly, households that experience migration are similar to disrupted families which may lead to negative psychological effects on children. This consequently has a bearing on the educational performance of children (Bennett et al., 2012; Kandel \& Kao, 2001). Secondly, owing to migration, rearing along with housework responsibilities are placed on the children who are left behind which affects the time allocated to schooling. Moreover, the children who are left behind have to assume the role of their parents as the breadwinner and hence join the workforce at an earlier age, taking on the role of the parent for the younger siblings (Booth \& Tamura, 2009; McKenzie \& Rapoport, 2010). Thirdly, if children develop a perception that their parents can earn higher wages as a result of migrating to a foreign country then it greatly reduces the incentives of children to attain more education. For instance, migration might be seen as an alternate route of achieving economic success without attaining higher educational levels (Kandel \& Kao, 2001).

By incorporating parental absenteeism, this study offers a unique framework that combines the impact of parental absenteeism and remittances on human capital formation in the source country through human capital accumulation of the children left behind. Moreover, adding the aspect of parental absenteeism is imperative for more fully understanding the implications of international migration because the absence of a migrant parent might negatively affect the human capital accumulation of the child. Thus, the net effect of international migration would be dependent upon whether the child's time spent on education or parental absenteeism has a larger effect.

We find threshold conditions for the relative wage in the source to destination countries beyond which unskilled migration helps reduce child labor and increase human capital. Moreover, the threshold is endogenous and depends on the sensitivity of human capital formation to parental absenteeism relative to the child's time spent on acquiring human capital. In the special case when the former is equal to the latter, the wages in the destination country should at least be twice as much as in the source country to have a detrimental (promoting) impact on child labor (human capital formation). Since the importance of parental absenteeism would depend on a variety of sociocultural factors such as marriage, presence of 
extended families, religious communities, and social networks, there will be heterogeneity in the impact of unskilled migration.

The organization of the rest of the paper is as follows: section 2 describes the model setup, section 3 solves the decision problems of parents, section 4 looks at the impact of unskilled migration on human capital formation of children while section 5 presents the concluding remarks and policy recommendations.

\section{Model Setup}

We utilize a two-period lived overlapping generations model of one parent and one child in a world that comprises two economies, the destination country (denoted as D) and the source country (denoted as S). There is no population growth and the size of population is fixed at N. We model the behavior of agents in the source country and examine the case of temporary migration. Total population of the adults of generation $(t)$ in the source country is further sub-divided into skilled workers, Ls;t, and unskilled workers, $\mathrm{L}_{\mathrm{u}, \mathrm{t}} \mathrm{N}_{t}^{S}=\mathrm{L}_{\mathrm{s}, \mathrm{t}}+\mathrm{L}_{\mathrm{u}, \mathrm{t}}{ }^{1}$

We are interested in modelling the migration decision of unskilled workers from a relatively poor source country. Hence, we assume no migration by the skilled workers. ${ }^{2}$ There is a wage premium associated with migration. Specifically,

$$
\alpha=\frac{w_{u, t}^{D}}{w_{u, t}^{S}}>1
$$

where $w_{u, t}^{D}$ and $w_{u, t}^{S}$ are the wage that an unskilled worker earns in the destination and source country, respectively. Migrating parents leave their children behind in the source country and send back remittances to finance their expenditures. Parents jointly decide the time spent in the destination country as a migrant, the amount of remittances to be sent to the child left behind in the source country and the child's time investment in education. All parents are identical and endowed with one unit of time that they devote to working. They spend a fraction $\delta_{2, t} \epsilon(0,1)$ of their unit endowment in the destination country as a temporary migrant. Similarly, all children of the

\footnotetext{
${ }^{1}$ Since we focus on modelling the behaviour of unskilled migrants, we simplify the model by excluding the skilled sector. The skilled sector would employ human capital, with each unit of human capital producing one unit of output, i.e. $\mathrm{Y}_{\tau, \mathrm{h}}=\mathrm{H}_{\tau}$. We could use this setup to find the overall growth rate in the economy.

${ }^{2}$ This is to focus on the implications of unskilled migration. For the skilled migration, see Dessy and Rambeloma (2009), and Camacho and Shen (2010).
} 
generation $(t+1)$ are endowed with one unit of time which they divide between obtaining education and working. If $e_{t+1}$ is the time devoted to education, then, $\left(1-e_{t+1}\right)$ is the time allocated to child labour. ${ }^{3}$

The individual preferences are represented by the following utility function

$$
U_{2, t}=\ln C_{2, t}+\gamma\left[\ln C_{1, t+1}+\beta \ln H_{2, t+1}\right]
$$

where $C_{2, t}$ is the consumption of the parent, $C_{1, t+1}$ is the consumption of the child, $\gamma>0$ is the parental altruism parameter, $\beta \in(0,1)$ is the discounting factor, and $\mathrm{H}_{2, \mathrm{t}+1}$, is the stock of human capital of a child.

The child devoting $e_{t}+1$ time in obtaining education would end up accumulating human capital level, $\mathrm{H}_{2, \mathrm{t}+1}$, given by the following technology

$$
H_{2, t+1}=\lambda H_{t} e_{t+1}^{\sigma 1}\left(1-\delta_{2, t}\right)^{\sigma 2}, \quad 1>\sigma_{1}, \sigma_{2}>0
$$

where $\lambda>1$ is the productivity parameter, $\left(1-\delta_{2, t}\right)$ is the time spent by the parent in the source country, and $H_{t}$ is the mean human capital of teachers from generation $t$. When defined in this way, human capital accumulation technology takes into account the adverse effect of parental absenteeism. There are various reasons to believe that the left behind children of a migrant parent experience a negative effect. First, children are deprived of direct input of parental effort in their human capital. Second, the households with migrating parents may face disruption that exert negative psychological effects on children. Third, the absence of a parent may place housework responsibilities on children. Fourth, if children develop a perception that their parents can earn higher wages as a result of migrating to a foreign country with limited skills, then, it greatly reduces their incentives to attain greater educational. All these factors individually or jointly can have adverse effects on the child's human capital. The net impact of parental absenteeism would depend on the sensitivity of human capital to parental absenteeism represented by $\sigma_{2}$. The smaller the $\sigma_{2}$ is, the less important will be the parental absenteeism in determining child's human capital. The size of the parameter $\sigma_{2}$ depends on a variety of social factors such as marriage systems, presence of extended families, religious communities, and social networks in general that would differ across countries. For instance, joint family systems, presence of extended families, cousin marriages, good social

\footnotetext{
${ }^{3}$ Since all individuals are identical, we skip the individual subscript $i$ for all variables.
} 
networks in terms of good neighbors are all likely to reduce the value of $\sigma_{2}$. A small value of $\sigma_{2}$ implies that a child's human capital formation is less sensitive to parental absenteeism, thereby reducing the negative impact of migration. On the other hand, nuclear families, broken marriages, absence of extended families and poor social networks are all likely to increase the value of $\sigma_{2}$, thereby making parental absenteeism due to migration more damaging for a child's accumulation of human capital.

The total income of a migrating parents is the sum of income earned in the source and destination country, i.e. $I_{t}=(1-\delta) \omega_{u, t}^{D}+\delta \omega_{u, t}^{D}$. We assume that the income earned in the destination country is high enough for parents to not only finance their consumption but also send remittances to their left behind children.

$$
I_{t}^{D}=\delta \omega_{u, t}^{D}=C_{t}^{D}+\theta_{t}
$$

where $\theta_{t}$ is the amount of remittances sent by the migrant parent. ${ }^{4}$ Moreover, we assume that parents spend their entire income earned in the source country on their consumption,

$$
I_{t}^{S}=\left(1-\delta_{t}\right) \omega_{u, t}^{S}+C_{t}^{S}
$$

The consumption of left behind children is financed by the remittances sent by their migrant parents and their own child labor income

$$
\begin{aligned}
C_{t+1} & =\theta_{t}+I_{t+1} \\
& =\delta \omega_{u, t}^{D}-C_{t}^{D}+\left(1-e_{t+1}\right) \omega_{u}^{k}
\end{aligned}
$$

where $\omega_{u}^{k}$ is the child labor wage earned by children.

There is a unique final good produced by two different technologies in the unskilled sector. The total output of the unskilled sector in the source country, $Y_{\tau, u}$, at any time $\tau, \tau=1,2$ is the sum of output produced by the unskilled adults and child labor

$$
Y_{\tau, u}=Y_{\tau, u}^{\alpha}+\phi Y_{\tau, u}^{k}
$$

The unskilled sector is sub-divided into two sectors. First one uses unskilled adults and physical capital, the second one which is relatively

\footnotetext{
${ }^{4}$ Since parents live only one adulthood period, we do not use time sub-script throughout the paper.

${ }^{5}$ This is assumed to highlight the financial constraint that unskilled workers face in the source country.
} 
less productive employs unskilled children and physical capital, where $1>$ $\phi>0$, and a and $\mathrm{k}$ represents the adult and children sectors, respectively.

Besides households, there also exists a fixed number $K$ of childless capitalists. ${ }^{6}$ Each capitalist has a one unit endowment of capital, hence, $K$ is also the total stock of capital in the economy. The capitalist may begin a firm combining her unit of capital with either adult labor or a child labor to produce output. There is a perfect capital mobility between the two sectors. The representative firm's output in the adult sector is

$$
Y_{\tau, u}^{\alpha}=L_{t}^{\mu}
$$

While that in the child sector is

$$
Y_{t}^{k}=\phi L_{t+1}^{\mu}
$$

where $\mu \epsilon(0,1)$.

Total labor supply is given by $\bar{L}_{t}-M$ in the adult sector, and $\bar{L}_{t}+1$ in the child labor sector, and $M$ denotes the number of unskilled adults who migrate. $\bar{L}_{t}+1$ is then also the total incidence of child labor in the economy. Given this, labor and inter-sectoral capital allocation constraints are

$$
L_{t+1} \leq \bar{L}_{t+1} ; \quad L_{t} \leq \bar{L}_{t}-M ; \quad K^{k}+K^{\alpha}=K
$$

Markets cleaning wages in each sector are, then, given by the marginal product of labor, i.e.

$$
\begin{aligned}
& w_{u, t}^{S}=\mu\left(\frac{K^{\alpha}}{\bar{L}_{t}-M}\right)^{1-\mu} \\
& w_{u}^{k}=\mu \phi\left(\frac{K^{k}}{\bar{L}_{t+1}}\right)^{1-\mu}
\end{aligned}
$$

where $w_{u, t}^{S}$ denotes the wage for the unskilled adult labor, and $w_{u}^{k}$ denotes the wage for child labor.

As the owner of the firm, a capitalist would claim a residual after production. This residual is $\pi_{\tau, u}^{\alpha}=Y_{\tau, u}^{\alpha}-w_{u, t}^{S} \bar{L}_{t}$ for the adult sector and

\footnotetext{
${ }^{6}$ We assume childless capitalists to abstain from focusing on the work/education decision of capitalists.
} 
$\pi_{\tau, u}^{k}=Y_{\tau, u}^{k}-w_{u}^{k} \bar{L}_{t+1}$ for the child sector. The returns to capital for the adult and child labor sectors are as follows

$$
\begin{aligned}
& \pi_{\tau, u}^{\alpha}=\left(\frac{\bar{L}_{t}-M}{K-K^{k}}\right)^{\mu}(1-\mu) \\
& \pi_{\tau, u}^{k}=\phi\left(\frac{\bar{L}_{t+1}}{K^{k}}\right)^{\mu}(1-\mu)
\end{aligned}
$$

Capital is perfectly mobile across sectors and the no arbitrage condition would imply that the returns to capital are equal in equilibrium, i.e. $\pi_{\tau, u}^{\alpha}=\pi_{\tau, u}^{k}$

$$
K^{k}=\frac{\phi^{\frac{1}{\mu}} \bar{L}_{t} K}{\left(\bar{L}_{t+1}-M\right)+\phi^{\frac{1}{\mu}} \bar{L}_{t}} ; \quad K^{\alpha}=\frac{\left(\bar{L}_{t+1}-M\right) K}{\left(\bar{L}_{t+1}-M\right)+\phi^{\frac{1}{\mu}} \bar{L}_{t}} ;
$$

Finally, by substituting in for capital, the wages in the unskilled adult and child sectors are give as follows

$$
\begin{aligned}
& w_{u, t}^{S}=\mu\left(\frac{K}{\bar{L}_{t+1}-M+\phi^{\frac{1}{\mu}} \bar{L}_{t}}\right)^{1-\mu} \\
& w_{u}^{k}=\mu \phi^{\frac{1}{\mu}}\left(\frac{K}{\bar{L}_{t+1}-M+\phi^{\frac{1}{\mu}} \bar{L}_{t}}\right)^{1-\mu}
\end{aligned}
$$

\section{The Decision Problems of Parents}

Parents jointly decide about the proportion of their time to be spent in the destination country $\delta_{2, t}$, the remittance amount, $\theta_{t}$, to be sent back to the child in the source country, as well as the proportion of time, $e_{t+1}$, their child devotes to education. Thus, the maximization problem of the household is as follows:

$$
\underset{\left(\theta_{t}, e_{t}, \delta\right)}{\max } U_{t}=\ln C_{2, t}+\gamma\left[\ln C_{1, t+1}+\beta \ln H_{2, t+1}\right]
$$

subject to:

$$
H_{2, t+1}=\lambda H_{t} e_{t+1}^{\sigma 1}\left(1-\delta_{2, t}\right)^{\sigma 2}, \quad 1>\sigma_{1}, \sigma_{2}>0
$$

$C_{2, t}$ and $C_{1, t+1}$ follow by definition as described in Section $2,0 \leq e_{t+1} \leq$ 
1 and $0 \leq \delta_{2, t} \leq 1$. Given this, the household value function is as follows

$$
\begin{gathered}
\theta_{t}, e_{t}, \delta_{t}=\ln \left(\delta_{2, t} w_{u, t}^{D}+\left(1-\delta_{2, t}\right) w_{u, t}^{S}-\theta_{t}\right)+\gamma\left[\ln \left(\theta_{t}+\left(1-e_{t+1}\right) w_{u}^{k}\right)+\right. \\
\left.\beta \ln \left\{\lambda H_{t} e_{t+1}^{\sigma 1}\left(1-\delta_{2, t}\right)^{\sigma 2}\right\}\right]
\end{gathered}
$$

The parents maximize this value function with respect to $\theta_{t}, e_{t+1}$ and $\delta_{2, t}$. The first order conditions are as follows

$$
\begin{aligned}
& \frac{d V}{d \theta_{t}}=\frac{1}{\delta_{2, t} w_{u, t}^{D}+\left(1-\delta_{2, t}\right) w_{u, t}^{S}-\theta_{t}}+\frac{\gamma}{\theta_{t}+\left(1-e_{t+1}\right) w_{u}^{k}}=0 \\
& \theta_{t}=\frac{\gamma \delta_{2, t} w_{u, t}^{D}+\gamma\left(1-\delta_{2, t}\right) w_{u, t}^{S}-\left(1-e_{t+1}\right) w_{u}^{k}}{(1+\gamma)} \\
& \frac{d V}{d e_{t+1}}=\gamma\left(\frac{-w_{u}^{k}}{\theta_{t}+\left(1-e_{t+1}\right) w_{u}^{k}}+\frac{\beta \sigma_{1} \lambda H_{t} e_{t+1}^{\sigma 1-1}\left(1-\delta_{2, t}\right)^{\sigma 2}}{\lambda H_{t} e_{t+1}^{\sigma 1}\left(1-\delta_{2, t}\right)^{\sigma 2}}\right)=0 \\
& e_{t+1}=\frac{\beta \sigma_{1}\left(\theta_{t}+w_{u}^{k}\right)}{w_{u}^{k}\left(1+\beta \sigma_{1}\right)} \\
& \frac{d V}{d \delta_{2, t}}=\frac{w_{u, t}^{D}-w_{u, t}^{S}}{\delta w_{u, t}^{D}+\left(1-\delta_{2, t}\right) w_{u, t}^{S}-\theta_{t}}-\frac{\gamma \beta \sigma_{2} \lambda H_{t} e_{t+1}^{\sigma 1}\left(1-\delta_{2, t}\right)^{\sigma 2-1}}{\lambda H_{t} e_{t+1}^{\sigma 1}\left(1-\delta_{2, t}\right)^{\sigma 2}}=0 \\
& \delta_{2, t}=\frac{\beta \sigma_{2}\left(\theta+w_{u}^{k}\right)-(1-\delta)\left(w_{u, t}^{D}-w_{u, t}^{S}\right)}{\beta \sigma_{2} w_{u}^{k}}
\end{aligned}
$$

Solving the first order conditions simultaneously yields the optimal time spent as a migrant, $\delta_{2, t}=\delta^{*}$, the optimal amount of remittances, $\theta_{t}=$ $\theta^{*}$, and the optimal time spent on children's schooling, $e_{t+1}=e^{*}$, as follows

$$
\begin{aligned}
\theta^{*} & =\frac{\gamma\left(1+\beta \sigma_{1}\right) w_{u, t}^{D}-w_{u}^{k}\left(1+\gamma \beta \sigma_{2}\right)}{x} \\
e^{*} & =\frac{\gamma \beta \sigma_{1}}{x}\left(\frac{w_{u, t}^{D}}{w_{u}^{k}}+1\right) \\
\delta^{*} & =\frac{1+\gamma\left(1+\beta \sigma_{1}\right)}{x}-\left[\frac{\gamma \beta \sigma_{2}\left(w_{u, t}^{S}+w_{u}^{k}\right.}{x\left(w_{u, t}^{D}-w_{u, t}^{S}\right.}\right]
\end{aligned}
$$


Where $x=1+\gamma+\gamma \beta\left(\sigma_{1}+\sigma_{2}\right)$. An increase in the unskilled worker's wage in the destination country increases the amount of remittances which in turn increases the children's time spent on education. On the other hand, an increase in the child's wage reduces the remittance flows, consequently reducing the children's time spent on education.

By substituting in for equation (1) and the wages in equations (4) and (5), the optimal values of $\theta^{*}, e^{*}, \delta^{*}$ are give as follows

$$
\begin{aligned}
& \delta^{*}=\frac{\mu K^{1-\mu}}{\left.x\left(\bar{L}_{t}-M\right)+\phi^{\frac{1}{\mu}} \bar{L}_{t+1}\right)^{1-\mu}}\left[\gamma\left(1+\sigma_{1} \beta\right) \alpha-\phi^{\frac{1}{\mu}}\left(1+\gamma \beta \sigma_{2}\right)\right] \\
& e^{*}=\left(\frac{\gamma \beta \sigma_{1}}{x}\right)\left(\frac{\alpha+\phi^{\frac{1}{\mu}}}{\phi^{\frac{1}{\mu}}}\right) \\
& \left(1-\delta^{*}\right)=\frac{\gamma \beta \sigma_{2}\left(\alpha+\phi^{\frac{1}{\mu}}\right)}{x(\alpha-1)}
\end{aligned}
$$

Where $\left(1-\delta^{*}\right)$ is the optimal time spent in the source country by an unskilled adult.

Proposition 1 A higher relative wage of unskilled workers in the destination country reduces child labor. There exists a threshold $\alpha=\phi^{\frac{1}{\mu}}\left(\frac{1+\gamma+\gamma \beta \sigma_{2}}{\gamma \beta \sigma^{1}}\right)=$ $\bar{\alpha}$, such that $\forall \alpha \geq \bar{\alpha}$, there is no child labor.

Proof. As follows

The time spent in child labor is given by $1-e_{t}^{*}$. From the above equation $\frac{\partial e^{*}}{\alpha}>0$, thus, $1-e_{t}^{*}$ decreases with the relative wage of unskilled workers in the destination country, $\alpha$. When $\alpha=\bar{\alpha}=\phi^{\frac{1}{\mu}}\left(\frac{1+\gamma+\gamma \beta \sigma_{2}}{\gamma \beta \sigma^{1}}\right), 1-$ $e_{t}^{*}=0$.

Intuitively, a higher relative wage in the destination country increases the time spent as a migrant as well as the amount of resources remitted back to the source countries. These remittances reduce the financial constraints of the migrant family and hence its reliance on the child labor as a source of family income. This is consistent with the empirical findings in the Cox Edwards and Ureta (2003) who reported that remittances significantly reduce the hazard of children drop out from school irrespective of the amount of remittances received. Moreover, the threshold $a$ is a positive 
function of the productivity in the child labor sector implying that with a more productive child labor sector a higher relative wage would be required to eliminate the child labor. Thus, the policies in the destination countries that promote better wages for unskilled immigrants as well as the policies in the source countries that reduce child labor productivity would result in more schooling and lower incidence of child labor.

Second, the threshold $\bar{\alpha}$ is also a positive function of $\sigma_{2} \cdot \sigma_{2}$ represents the sensitivity of human capital accumulation to parental absenteeism, and a higher value of $\sigma_{2}$ would imply a higher sensitivity. Intuitively, when human capital technology is more sensitive to parental absenteeism, the relative return from spending more time in schooling is lower. This, in turn, makes schooling less attractive and child labor more attractive. As a result, a greater relative wage in the destination country would be required to eliminate child labor.

\section{Human Capital Formation}

In this section, we derive the human capital equation of children. Human capital of the children from $t+1$ generation is given by

$$
H_{2, t+1}=\lambda H_{t} e_{t+1}^{\sigma 1}\left(1-\delta_{2, t}\right)^{\sigma_{2}}
$$

By substituting in for the optimal time allocation to schooling and the optimal time spent in the source country from the equations (8) and (9), respectively, the level of human capital of the unskilled workers' children is given by;

$$
H_{t+1}=\frac{\lambda H_{t}\left(\gamma \beta \sigma_{1}\right)^{\sigma_{1}}\left(\gamma \beta \sigma_{2}\right)^{\sigma_{2}}\left(\alpha+\phi^{\frac{1}{\mu}}\right)^{\sigma_{1}+\sigma_{2}}}{\left[1+\gamma+\gamma \beta\left(\sigma_{1}+\sigma_{2}\right)\right]^{\sigma_{1}+\sigma_{2}}\left(\phi^{\frac{1}{\mu}}\right)^{\sigma_{1}}(\alpha-1)^{\sigma_{2}}}
$$

Proposition 2 There is a non-monotonic relationship between the relative wages of the unskilled workers in the destination country and their children's human capital. There exists a threshold $\alpha=1+\frac{\sigma_{2}}{\sigma_{1}}\left(1+\phi^{\frac{1}{\mu}}\right)=\alpha_{A}$ such that for $\forall \alpha<$ $\alpha_{A}$, there is a negative impact of migration on the children's human capital, and $\forall \alpha \geq \alpha_{A}$, migration leads to higher levels of human capital.

Proof. See Appendix A 
Intuitively, the relative wage of the unskilled workers in the destination country affects their children's human capital in two ways. First, a higher relative wage would lead to more time spent in the destination country as well as a higher amount of the remittances sent back to children. Consequently, there would be an increase in the schooling (a higher $e_{t}^{*}$ ) of the children left behind, which would increase the level of their human capital. Second, more time spent in the destination country implies a less time $\left(1-\delta^{*}\right)$ spent with children which negatively affects their human capital. Which of the two effects dominate crucially depend on the magnitude of the relative wage, $\alpha$. Moreover, the threshold $\alpha_{A}$ that demarcates the positive impact of relative wage on human capital from its negative impact crucially depends on the sensitivity of human capital technology to the parental absenteeism relative to the effort in schooling, $\frac{\sigma_{2}}{\sigma_{1}} \cdot \sigma_{2}$ shows the importance of the parental time spent in the source country in shaping the level of human capital of their children. Thus, when human capital accumulation technology is more sensitive to parental absenteeism, there is a greater chance of a negative impact of migration on children's human capital. In an extreme case where $\sigma_{2}=0$, migration always leads to higher levels of human capital. In a special case, when the effort in schooling and parental absenteeism are equally important i.e. $\sigma_{2}=\sigma_{1} \Rightarrow \alpha_{A}=2+\phi^{\frac{1}{\mu}}$, the wage in the destination country has to be more than twice as much as that in the source country to have a positive impact on children's human capital. Overall, the threshold $\alpha_{A}$ would be higher with higher (lower) sensitivity of human capital formation to parental absenteeism (effort in schooling) and higher productivity of the child labor sector.

Since the importance of parental absenteeism would depend on a variety of sociocultural factors such as marriage, presence of extended families, religious communities, and social networks, there will be heterogeneity in the impact of unskilled migration. From a policy point of view, a policy that reduces the sensitivity of children's human capital on parental absenteeism would make unskilled migration conducive for human capital accumulation. Furthermore, policies in the destination country that raises wages of unskilled workers, and/or policies in the source country that reduces productivity of child labor sector would induce a positive impact of unskilled migration on human capital of the children left behind.

\section{Conclusion}

Despite having a wealth of empirical literature on the implications of unskilled migration on children's education in the source country, there is a 
dearth of a coherent theoretical framework linking unskilled migration and parental absenteeism to the human capital of the children left behind. We fill this gap by offering a framework that takes into account the joint decision of unskilled migration, the amount of remittances, and the effort exerted in children's schooling. Our results highlight the key role of relative wages of unskilled workers in the destination country in determining the impact of migration on child labor and human capital of left behind children. However, there are threshold effects in the size of this relative wage that determine the direction of the impact of unskilled migration. Moreover, these thresholds are endogenous and crucially depend on the sensitivity of human capital accumulation to parental absenteeism and the productivity of child labor sector. Since, the sensitivity of human capital would depend on sociocultural factors, our results suggest heterogeneity in the impact of migration on child labor and human capital of left behind children.

Our results propose important policy implications for developing countries. Developing countries can encourage the migration of unskilled migration to curb the child labor. The remittances sent back by the unskilled migrants play a major role in promoting school enrolment and reducing child labor by shifting the use of children's time towards education and away from working. Our results recommend three dimensional policies for the developing countries to harness the positive impact of unskilled migration. First, developing countries should devote efforts and resources to improve the matching between unskilled migrants and the host employers to improve their productivity and the relative wage. This could, for example, include designing well grounded labour market information systems. The systems which accurately assess labour market needs and the skill requirements, disseminate such information through innovative ways that are easily accessible to low-skilled workers, and provide training and match making opportunities. Second, within the source country, governments need to provide a conducive schooling environment such that the impact of parental absenteeism is minimized. This could include policies such as better access to schools and group or neighborhood based monitoring and evaluation of the schools. And third, policies are required to hamper the productivity of child labor sector, which will reduce the opportunity cost of schooling. This could include the policies that disincentivize child labor production sector such as mandatory registration with the government (documentation), penalty or higher taxes, as well as the policies that incentivise identification and punishment of child labor cases, and mandatory schooling. 


\section{References}

Acosta, P. (2006). Labor Supply, School Attendance, and Remittances from International Migration: the case of El Salvador. Policy Research Working Paper Series 3903, The World Bank.

Ahn, P. (2004). Migrant Workers and Human Rights: Out-Migration from South Asia. International Labour Organization.

Arif, R., \& Chaudhry, A. (2015). The effects of external migration on enrolments, accumulated schooling and dropouts in Punjab. Applied Economics, 47(16), 1607-1632.

Beine, M., Docquier, F. \& Rapoport, H. (2001). Brain Drain and Economic Growth: Theory and Evidence. Journal of Development Economics, vol. 64 (1), pp. 275-289.

Beine, M., Docquier, F. \& Rapoport, H. (2008). Brain Drain and Human Capital Formation in Developing countries: Winners and Losers. The Economic Journal, vol. 118, pp. 631-652.

Bennett, R., Clifford, D., \& Falkingham, J. (2012). Household Members' Migration and the Education of Children 'Left Behind': Empirical Findings from Tajikistan and Reflections for Research Practice. Population, Space and Place, vol. 19 (1), pp. 1-14.

Bhagwati, J. \& Hamada, K. (1974). The Brain Drain, International Integration of Markets for Professionals and Unemployment: A theoretical analysis. Journal of Development Economics, vol. 1(1), pp. 19-42.

Booth, A. \& Tamura, Y. (2009). Impact of Paternal Temporary Absence on Children Left Behind. IZA Discussion Papers 4381, Institute for the Study of Labor (IZA).

Calero, C., Bedi, A.S. \& Sparrow, R. (2009). Remittances, Liquidity Constraints and Human Capital Investments in Ecuador. World Development, vol. 37(6), pp. 1143-1154.

Camacho, C. \& Shen, I-L. (2010). Public Education for the Children Left Behind. IZA Discussion Papers 4833, Institute for the Study of Labor (IZA). 
Chen, H.J. (2006). International Migration and Economic Growth: A Source Country Perspective. Journal of Population Economics, vol. 19 (4), pp. 725-748.

Cox Edwards, A. \& Ureta, M. (2003). International Migration, Remittances, and Schooling: Evidence from El Salvador. Journal of Development Economics, vol. 72 (2), pp. 429-461.

Dessy, S. \& Rambeloma, T. (2009). Immigration Policy, Remittances and Growth in the MigrantSending Country. Cahier de recherche/ Working Paper 09-15, CIRPEE.

Docquier, F. (2006). Brain Drain and Inequality Across Nations. IZA Discussion Paper No. 2440.

Dorantes, C.A., Georges, A. \& Pozo, S. (2010). Migration, Remittances, and Children's Schooling in Haiti. Annals of the American Academy of Political and Social Science, vol. 630, pp. 224-244.

Ebeke, C.H. (2012). The Power of Remittances on the International Prevalence of Child Labor. Structural Change and Economic Dynamics, vol. 23, pp. 452- 462.

Faini, R. (2007) Remittances and the Brain Drain: Do more skilled migrants remit more?. World Bank Economic Review 21(2): 177-91.

Hanson, G.H. \& Woodruff, C. (2003). Emigration and Educational Attainment in Mexico. University of California at San Diego, Mimeographed.

Kandel, W., \& Kao, G. (2001). The Impact of Temporary Labor Migration on Mexican Children's Educational Aspirations and Performance. International Migration Review, vol. 35 (4), pp.1205-1231.

Mansuri, G. (2006). Migration, School Attainment, and Child Labor: Evidence from Rural Pakistan. Policy Research Working Paper Series 3945, The World Bank.

Marchiori, L., Pieretti P. \& Zou, B. (2010). Migration and human capital in an endogenous fertility model. Annals of Economics and Statistics, vol. 97-98, pp. 187-205.

Mayr, K. \& Peri, G. (2009). Brain Drain and Brain Return: Theory and Application to Eastern- Western Europe. The B.E. Journal of Economic Analysis \& Policy, vol. 9(1), pp.1-52. 
McKenzie, D. \& Rapoport, H. (2010). Can Migration Reduce Educational Attainment? Evidence from Mexico. Journal of Population Economics, vol. 24(4), pp.1331-1358.

Mountford, A. (1997). Can a brain drain be good for growth in the source economy? Journal of Development Economics, vol. 53(2), pp. 287-303.

Nimi, Y., Ozden, C. \& Schiff, M. (2010). Remittances and the Brain Drain: Skilled Migrants Do Remit Less. Annals of Economics and Statistics No. 97/98, pp. 123-141.

Rapoport, H. (2002). Who is afraid of the brain drain? Human capital flight and growth in developing countries, SIEPR Policy Brief, Stanford University.

Ratha, D., Mohapatra, S. \& Silwal, A. (2011). Migration and Remittances Factbook 2011. World Bank.

Richard, H \& Adams, J. (2009). The Determinants of International Remittances in Developing Countries. World Development, vol. 37(1), pp. 93-103.

Stark, O. \& Wang, Y. (2002). Inducing human capital formation: migration as a substitute for subsidies. Journal of Public Economics, vol. 86(1), pp.29-46.

Yang, D. (2008). International Migration, Remittances, and Household Investment: Evidence from Philippine Migrants' Exchange Rate Shocks. Economic Journal, vol. 118 (528), pp. 591-630. 


\section{Appendix A}

In this appendix, we derive the level of human capital of the unskilled workers' children and then show a detailed comparative static analysis of $H^{*}$. The children's human capital is given by

$$
H_{2, t+1}=\lambda H_{t} e_{t+1}^{\sigma_{1}}\left(1-\delta_{2, t}\right)^{\sigma_{2}}
$$

By substituting in for the optimal values of $e^{*}$ and $(1-\delta)$ from the equation (8) and (9), respectively

$$
\begin{gathered}
H^{*}=\lambda H_{t}\left[\frac{\gamma \beta \sigma_{1}\left(\alpha+\phi^{\frac{1}{\mu}}\right)}{\left[1+\gamma+\gamma \beta\left(\sigma_{1}+\sigma_{2}\right)\right] \phi^{\frac{1}{\mu}}}\right]^{\sigma_{1}}\left[\frac{\gamma \beta \sigma_{2}\left(\alpha+\phi^{\frac{1}{\mu}}\right)}{\left[1+\gamma+\gamma \beta\left(\sigma_{1}+\sigma_{2}\right)\right](\alpha-1)}\right]^{\sigma_{2}} \\
H^{*}=\frac{\lambda H_{t}\left(\gamma \beta \sigma_{1}\right)^{\sigma_{1}}\left(\alpha+\phi^{\frac{1}{\mu}}\right)^{\sigma_{1}+\sigma_{2}}\left(\gamma \beta \sigma_{2}\right)^{\sigma_{2}}}{\left[1+\gamma+\gamma \beta\left(\sigma_{1}+\sigma_{2}\right)\right]^{\sigma_{1}+\sigma_{2}}(\alpha-1)^{\sigma_{2}}\left(\phi^{\frac{1}{\mu}}\right)^{\sigma_{1}}}
\end{gathered}
$$

Thus, following is the level of human capital of the unskilled workers' child in time period $t+1$ :

$$
H^{*}=\frac{\lambda H_{t}\left(\gamma \beta \sigma_{1}\right)^{\sigma_{1}}\left(\gamma \beta \sigma_{2}\right)^{\sigma_{2}}\left(\alpha+\phi^{\frac{1}{\mu}}\right)^{\sigma_{1}+\sigma_{2}}}{\left[1+\gamma+\gamma \beta\left(\sigma_{1}+\sigma_{2}\right)\right]^{\sigma_{1}+\sigma_{2}}\left(\phi^{\frac{1}{\mu}}\right)^{\sigma_{1}}(\alpha-1)^{\sigma_{2}}}
$$

on $H^{*}$

Derivating $H_{t+1}$ with respect to $\alpha$ shows a non-linear impact of $\alpha$

$$
\begin{aligned}
\frac{\partial H^{*}}{\partial \alpha} & =\frac{\lambda\left(\gamma \beta \sigma_{1}\right)^{\sigma_{1}}\left(\gamma \beta \sigma_{2}\right)^{\sigma_{2}}}{x^{\sigma_{1}+\sigma_{2}}\left(\phi^{\frac{1}{\mu}}\right)^{\sigma_{1}}}\left[\begin{array}{c}
(\alpha-1)^{\sigma_{2}}\left(\sigma_{1}+\sigma_{2}\right)\left(\alpha+\phi^{\frac{1}{\mu}}\right)^{\sigma_{1}+\sigma_{2}-1}(1) \\
-\left(\alpha+\phi^{\frac{1}{\mu}}\right)^{\sigma_{1}+\sigma_{2}} \sigma_{2}(\alpha-1)^{\sigma_{2}-1} \\
(\alpha-1)^{2 \sigma_{2}}
\end{array}\right] \\
& =\frac{\lambda\left(\gamma \beta \sigma_{1}\right)^{\sigma_{1}}\left(\gamma \beta \sigma_{2}\right)^{\sigma_{2}}}{x^{\sigma_{1}+\sigma_{2}}\left(\phi^{\frac{1}{\mu}}\right)^{\sigma_{1}}(\alpha-1)^{2 \sigma_{2}}}\left(\left[(\alpha-1)^{\sigma_{2}}\left(\alpha+\phi^{\frac{1}{\mu}}\right)^{\sigma_{1}+\sigma_{2}}\right]\left[\frac{\left(\sigma_{1}+\sigma_{2}\right)}{\left(\alpha+\phi^{\frac{1}{\mu}}\right)}-\frac{\sigma_{2}}{(\alpha-1)}\right]\right) \\
& =\frac{\lambda\left(\gamma \beta \sigma_{1}\right)^{\sigma_{1}}\left(\gamma \beta \sigma_{2}\right)^{\sigma_{2}}(\alpha-1)^{\sigma_{2}}\left(\alpha+\phi^{\frac{1}{\mu}}\right)^{\sigma_{1}+\sigma_{2}}}{x^{\sigma_{1}+\sigma_{2}}\left(\phi^{\frac{1}{\mu}}\right)^{\sigma_{1}}(\alpha-1)^{2 \sigma_{2}}}\left[\frac{\left(\sigma_{1}+\sigma_{2}\right)}{\left(\alpha+\phi^{\frac{1}{\mu}}\right)}-\frac{\sigma_{2}}{(\alpha-1)}\right]
\end{aligned}
$$




$$
=\frac{\lambda\left(\gamma \beta \sigma_{1}\right)^{\sigma_{1}}\left(\gamma \beta \sigma_{2}\right)^{\sigma_{2}}\left(\alpha+\phi^{\frac{1}{\mu}}\right)^{\sigma_{1}+\sigma_{2}}}{x^{\sigma_{1}+\sigma_{2}}\left(\phi^{\frac{1}{\mu}}\right)^{\sigma_{1}}(\alpha-1)^{\sigma_{2}}}\left[\frac{\left(\sigma_{1}+\sigma_{2}\right)}{\left(\alpha+\phi^{\frac{1}{\mu}}\right)}-\frac{\sigma_{2}}{(\alpha-1)}\right]
$$

The first term $\frac{\lambda\left(\gamma \beta \sigma_{1}\right)^{\sigma_{1}}\left(\gamma \beta \sigma_{2}\right)^{\sigma_{2}}\left(\alpha+\phi^{\frac{1}{\mu}}\right)^{\sigma_{1}+\sigma_{2}}}{x^{\sigma_{1}+\sigma_{2}}\left(\phi^{\frac{1}{\mu}}\right)^{\sigma_{1}}(\alpha-1)^{\sigma_{2}}}$ is positive. Therefore, the sign of the derivative depends upon the sign of the term $\left[\frac{\left(\sigma_{1}+\sigma_{2}\right)}{\left(\alpha+\phi^{\frac{1}{\mu}}\right)}-\frac{\sigma_{2}}{(\alpha-1)}\right]$. Checking the sign of the second term.

$$
\begin{aligned}
& {\left[\frac{\left(\sigma_{1}+\sigma_{2}\right)}{\left(\alpha+\phi^{\frac{1}{\mu}}\right)}-\frac{\sigma_{2}}{(\alpha-1)}\right] \gtreqless 0} \\
& \frac{\left(\sigma_{1}+\sigma_{2}\right)(\alpha-1)-\sigma_{2}\left(\alpha+\phi^{\frac{1}{\mu}}\right)}{\left(\alpha+\phi^{\frac{1}{\mu}}\right)(\alpha-1)} \gtreqless 0 \\
& \frac{\alpha \sigma_{2}+\alpha \sigma_{1}-\sigma_{2}-\sigma_{1}-\alpha \sigma_{2}-\sigma_{2} \phi^{\frac{1}{\mu}}}{\left(\alpha+\phi^{\frac{1}{\mu}}\right)(\alpha-1)} \gtreqless 0 \\
& \frac{\alpha \sigma_{1}-\sigma_{2}-\sigma_{1}-\sigma_{2} \phi^{\frac{1}{\mu}}}{\left(\alpha+\phi^{\frac{1}{\mu}}\right)(\alpha-1)} \gtreqless 0 \\
& \alpha \sigma_{1}-\sigma_{2}-\sigma_{1}-\sigma_{2} \phi^{\frac{1}{\mu}} \gtreqless 0 \\
& \frac{\partial H^{*}}{\partial \alpha}=0 \text { if }\left(\alpha \sigma_{1}-\sigma_{2}-\sigma_{1}-\sigma_{2} \phi^{\frac{1}{\mu}}\right)=0 \\
& \alpha \sigma_{1}-\sigma_{2}-\sigma_{1}-\sigma_{2} \phi^{\frac{1}{\mu}}=0 \\
& \alpha \sigma_{1}=\sigma_{2}+\sigma_{1}+\sigma_{2} \phi^{\frac{1}{\mu}} \\
& \alpha=\frac{\sigma_{2}+\sigma_{1}+\sigma_{2} \phi^{\frac{1}{\mu}}}{\sigma_{1}} \\
& \alpha=\frac{\sigma_{2}+\sigma_{2} \phi^{\frac{1}{\mu}}}{\sigma_{1}}+\frac{\sigma_{1}}{\sigma_{1}} \\
& \alpha=\frac{\sigma_{2}\left(1+\phi^{\frac{1}{\mu}}\right)}{\sigma_{1}}+1 \\
& \alpha=1+\frac{\sigma_{2}}{\sigma_{1}}\left(1+\phi^{\frac{1}{\mu}}\right)=\alpha_{A}
\end{aligned}
$$




$$
\begin{gathered}
\frac{\partial H^{*}}{\partial \alpha}>0 \text { if }\left(\alpha \sigma_{1}-\sigma_{2}-\sigma_{1}-\sigma_{2} \phi^{\frac{1}{\mu}}\right)>0 \\
\frac{\partial H^{*}}{\partial \alpha}>0 \text { if } \alpha>\left[1+\frac{\sigma_{2}}{\sigma_{1}}\left(1+\phi^{\frac{1}{\mu}}\right)\right] \\
\frac{d H_{t+1}}{d \alpha}>0 \text { if } \alpha>\alpha_{A} \\
\frac{\partial H^{*}}{\partial \alpha}<0 \text { if }\left(\alpha \sigma_{1}-\sigma_{2}-\sigma_{1}-\sigma_{2} \phi^{\frac{1}{\mu}}\right)<0 \\
\frac{\partial H^{*}}{\partial \alpha}<0 \text { if } \alpha<\left[1+\frac{\sigma_{2}}{\sigma_{1}}\left(1+\phi^{\frac{1}{\mu}}\right) \equiv \alpha_{A}\right] \\
\text { Hence } \frac{\partial H^{*}}{\partial \alpha}<0 \text { if } \alpha<\alpha_{A}
\end{gathered}
$$

